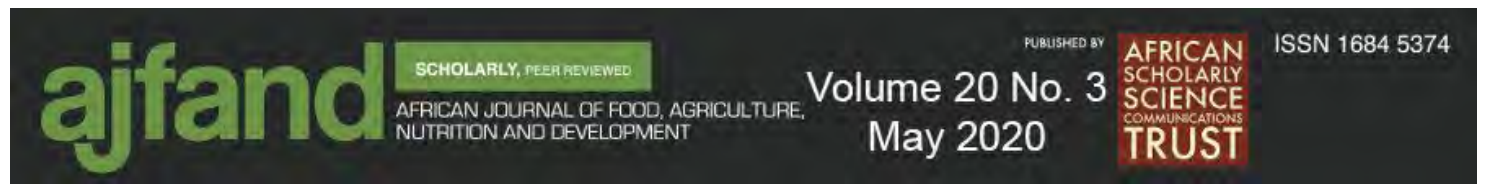

Afr. J. Food Agric. Nutr. Dev. 2020; 20(3):15954-15977_ DOI: 10.18697/ajfand.91.18255

PREVALENCE OF UNDERNUTRITION AND ASSOCIATED FACTORS AMONG PRESCHOOL CHILDREN IN JIMMA TOWN, SOUTH WEST ETHIOPIA

\title{
Melese $\mathrm{ST}^{2 *}$, Bedatu $\mathrm{G}^{1}$ and $\mathrm{H}$ Kalkidan ${ }^{2}$
}

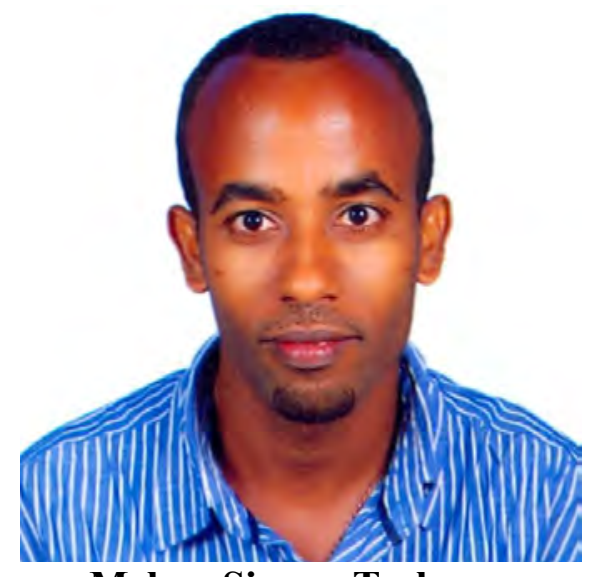

Melese Sinaga Teshome

*Corresponding author email: $\underline{\text { sinmele@gmail.com }}$

${ }^{1}$ Shane Gibe Hospital, Jimma Town, Oromia Region, Ethiopia

${ }^{2}$ Department of Nutrition and Dietetics, Faculty of Public Health, Health Institute, Jimma Ethiopia, P. O. Box 378, Jimma University, Ethiopia 


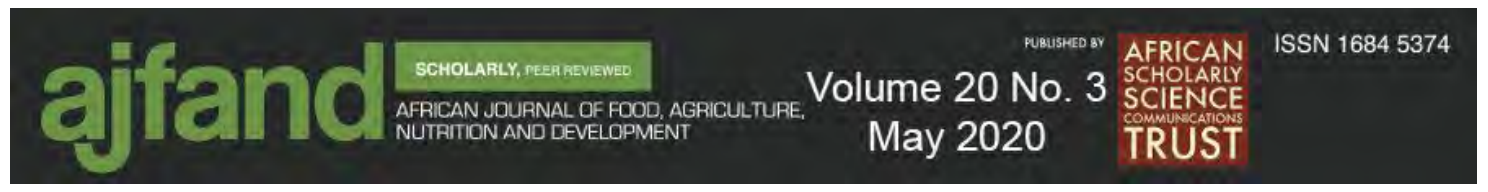

\begin{abstract}
Undernutrition is a major public health problem disproportionately high in the developing world. In Ethiopia, child undernutrition remained a key public health problem despite lots of interventions. According to 2016 EDHS, 38\% of children under age 5 are stunted; $10 \%$ are wasted, and $24 \%$ are underweight. Data specific to the nutritional status of preschool children in Jimma zone as well as the country is limited. The main objective of this study was to assess the prevalence of undernutrition and associated factors among preschool children in Jimma town. A community-based cross-sectional study was conducted among 408 preschool children 36-59 months aged in Jimma town from March 1-April 15/2018. Systematic sampling techniques were used in selecting the study participants. Data were exported from EPI data version 4.1 to SPSS version 20 for statistical analysis. Anthropometric data was analyzed by WHO Anthro (2006) and principal component analysis was done to generate house hold wealth index. Both descriptive and multivariable logistic regressions were used to identify independent predictors of nutritional status. Finally, variables with a p-value $<0.05$ was statistically significant. The prevalence of stunting, underweight and wasting was about $21.8 \%$, $15.2 \%$, and $17.2 \%$, respectively. This study showed that children from food-insecure households were 3.7 times stunted [AOR=3.731; (95\% CI=2.037-6.836)]; similarly, children whose mothers had no formal education were 3.9 times stunted [AOR $=3.98$; $(95 \% \mathrm{CI}=1.206-13.127)]$. In addition, children who share food from the same plate were 2.2 times stunted than their counterparts $[\mathrm{AOR}=2.228 ;(95 \% \mathrm{CI}=1.251-3.971)]$ and children who fed one to two times per day were 2.8 times more likely to be stunted as compared to those who fed four to five times per day $[\mathrm{AOR}=2.82(95 \% \mathrm{CI}=1.251$ 3.971)]. Furthermore, children from low socioeconomic status were 3.4 times wasted as compared to those children from high socioeconomic households $[\mathrm{AOR}=3.453(95 \% \mathrm{CI}$ $=1.255-9.510)$ ], children from family size of five and above were 3 times wasted than those children from family size less than five $[\mathrm{AOR}=3.090(95 \% \mathrm{CI}=1.198-7.972)]$. There existed a substantial level of stunting and wasting among preschool children. Maternal education, feeding on the same plate, frequency of feeding per day and household food security status was associated with stunting, while wasting was associated with family size, wealth index, age of mother and fever during the past 2 weeks.
\end{abstract}

Key words: undernutrition, Preschool children, associated factors, Ethiopia, Children, Stunting, Wasting and underweight 


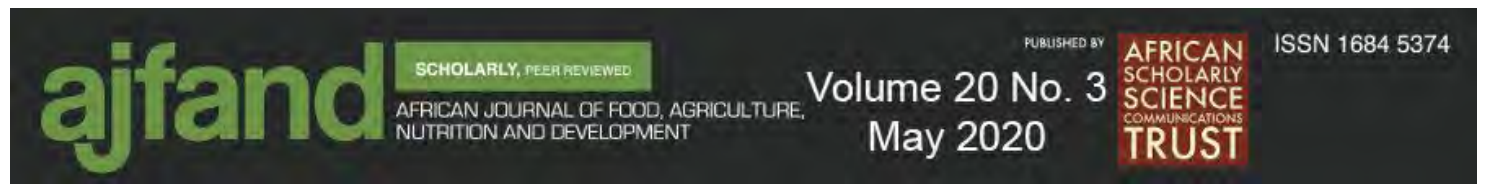

\section{INTRODUCTION}

Malnutrition is a major public health problem affecting every country $[1,2]$. It can result from unbalanced diets that do not contain all necessary nutrients such as inadequate or excessive consumption of nutrients resulting in undernutrition (Example wasting, stunting or underweight), micronutrient related malnutrition and increased risk for obesity and non-communicable diseases (NCDs) [1]. One in three people globally experiences some form of malnutrition [3].

The consequences of malnutrition range broadly from raised rates of death from infectious diseases and decreased learning capacity in childhood to increased noncommunicable diseases in adulthood [4]. Short-term consequences associated with undernutrition include maternal and childhood mortality, morbidity and disability undernutrition, and diet are now the largest risk factors responsible for the global burden of disease by far [5].

Improving linear growth for children under age two by 1 standard deviation adds about half a grade to school attainment [6]. In addition to the physical and cognitive consequences, undernutrition can have devastating effects on the economy. According to the World Bank, malnutrition affects the economy of a country in three ways: directly through a loss of productivity, indirectly through a loss of cognitive function, and losses caused by accrued health care costs [7]. On the other hand, prevention of undernutrition in early childhood leads to hourly earnings that are $20 \%$ higher and wage rates that are $48 \%$ higher; individuals who are $33 \%$ more likely to escape poverty; and women who are $10 \%$ more likely to own their own business [8]. According to the Cost of Hunger in Ethiopia 2013, the total annual cost of undernutrition in Ethiopia was estimated at ETB 55.5 billion (1.91 billion USD dollar), equivalent to $16.5 \%$ of GDP in 2009. According to the study, Ethiopia could reduce losses by ETB 148 billion (5.1 billion USD dollar) by 2025 if underweight rates were reduced to $5 \%$ and stunting to $10 \%$ in children under 5 . The study suggests reducing child undernutrition rates to half the current levels by 2025 could reduce losses by ETB 70.9 billion (2.44 billion USD dollar) [9]. These determinants are heavily influenced by the social status of women, as well as institutional/organizational, political and ideological, economic, and environmental constraints [10].

Undernutrition commonly affects all groups in a community, but infants and young children are the most vulnerable because of their high nutritional requirements for growth and development [11]. According to 2017 edition of UNICEF/ World Health Organization (WHO) / World Bank Group Joint Child Malnutrition Estimates, globally the number of under 5 -year children affected by stunting and wasting were estimated to be $154.8(22.9 \%)$ and 52 million (7.7\%) [12].

As outlined by UNICEF a child from food-insecure households will be malnourished (31). Food security is defined as "Food security exists when all people, at all times, have physical and economic access to sufficient, safe, and nutritious food that meets their dietary needs and food preferences for an active and healthy life". Being secured in food does not mean that there is adequate nutrition. It is one of the pillars of improving 


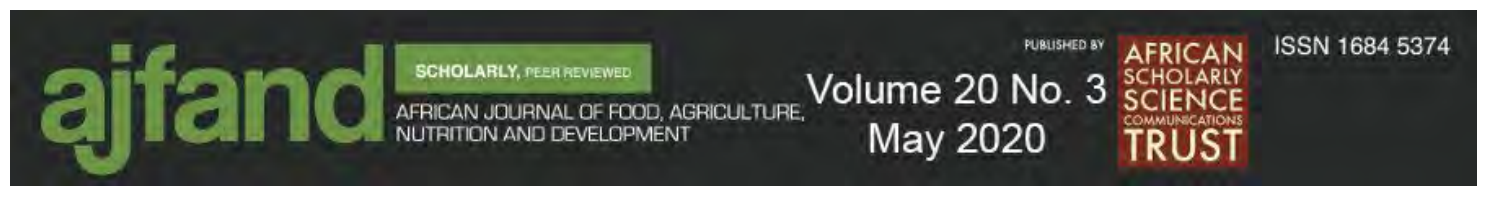

nutrition status but does not necessarily mean that children from food-secure households are well-nourished. Malnutrition is common in many food-secure households (30).

After the Millennium Development Goals (MDG), the proportion of underweight children was reported to have declined globally from $25 \%$ in 1990 to $15 \%$ in 2015 [13]. However, this decline was not evenly distributed in all regions of the world as nearly 90 percent of all underweight children reside in South East Asia and sub-Saharan Africa (SSA) [14]. According to the 2015 MDG report, SSA accounts for one-third of all undernourished children globally with about 39\% stunted, 10\%wasted and 25\% underweight children under five years of age [13].

The prevalence of stunting has decreased considerably from $58 \%$ in 2000 to $38 \%$ in 2016 , an average decline of more than 1 percentage point per year. On the other hand, the prevalence of wasting changed a little over the same period, with a wasting rate of $10 \%$ at the time of the EDHS 2016, which was the same level as in 2011. The prevalence of underweight has consistently decreased from $41 \%$ to $24 \%$ over the 16 years [15]. The prevalence of child stunting, wasting, and underweight among under 5 years in Oromia region was $30.6 \%, 9 \%, 27.4 \%$, respectively according to 2016 EDHS [15].

There are a few studies done on the prevalence of undernutrition among a preschool-age group at the national level. Data specific to preschool children's nutritional status in Jimma zone, Ethiopia is lacking, if any, it is presented as under-five children. Moreover, the shift in public health nutrition programs from under 5 to under 2 years of age is ignoring monitoring this important age groups. They are few published studies regarding prevalence of undernutrition and associated factors among preschool children aged 3-5 years in some areas of Ethiopia. There is no study done among preschool children in our study area. Therefore, the present study was designed to assess the prevalence of undernutrition and associated factors among preschool children aged 3-5 years in Jimma town.

\section{MATERIALS AND METHODS}

This study was conducted in Jimma town which is located $350 \mathrm{Km}$ from the capital city Addis Ababa in South West Ethiopia. According to information obtained from Jimma town municipality, the town has a total surface area of 4,623 hectares and has a population of 174,778 of which 87,879 are males and 86,999 are females and 31,000 were children under-five from which 17,545 were preschool children being distributed in 17 Kebeles (village). There are 5 public health institutions ( 3 health centers \& 2 hospitals) and 18 non-governmental health institutions owned by NGOs and private owners, which provide different services for the community (32). This study was conducted from March 1 to April 15, 2018. A community-based cross-sectional study design was employed.

The source population was all preschool children aged between 3-5 years old living in Jimma town. The study population was those randomly selected preschool children aged between 3-5 years old living in the selected Kebele of Jimma town. Inclusion criteria were all preschool children 3-5 years old whose parents or caregiver were residents of 


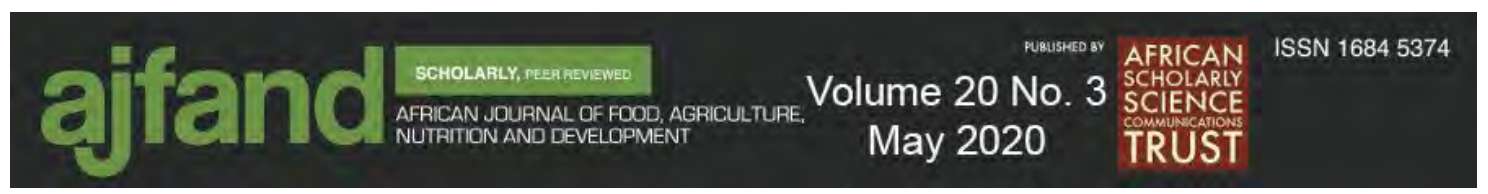

Jimma town for at least 6 months. Exclusion criteria were mother/caregiver who was seriously ill and unable to respond to the questionnaire, those children who have a skin infection (edematous), children who were seriously ill and in addition to this, for children diagnosed with severe malnutrition problems, referral papers were provided to take the child to the nearby health center.

\section{Sampling}

The sample size was calculated by sample size determination formula for a single population proportion (33)

$n=\frac{\left(Z_{1-a / 2}\right)^{2} p(1-p)}{d^{2}}$

With the following assumption:

$\mathrm{n}=$ sample size,

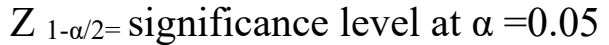

$\mathrm{d}=$ margin of error $(5 \%)$

$\mathrm{P}=$ Study done in Hawassa Zuria showed that prevalence of stunting, and wasting were $41 \%$, and $13.2 \%$, respectively among pre-school children [16].

Since the sample size for estimation of the prevalence of stunting was larger; it was taken because it can address both dependent and independent variables more than any other variables. Therefore, the subsequent reports were based on a total sample of 408 .

\section{Sampling procedure}

From 17 Kebeles found in Jimma town, 5 Kebeles were randomly selected using a lottery method based on WHO recommendation to include at least $30 \%$ of total Kebele(village). In these selected Kebele preliminary survey was conducted for one week before data collection to identify eligible preschool children with respective household. The determined sample was proportionally allocated to selected Kebele and value was calculated $\mathrm{k}=9$. Finally, the study unit was selected by using systematic sampling and first houses were selected by the lottery method. Then the preschool children in the selected household were interviewed and measurement of anthropometric indices was done. For households with more than one preschool children, only one was selected using the lottery method. If the selected household was closed during data collection, the interviewers revisited the household at different time intervals and if the children from the selected household were not available, they were excluded from the survey and replaced by the next nearest household. Based on this, 408 children were selected. 

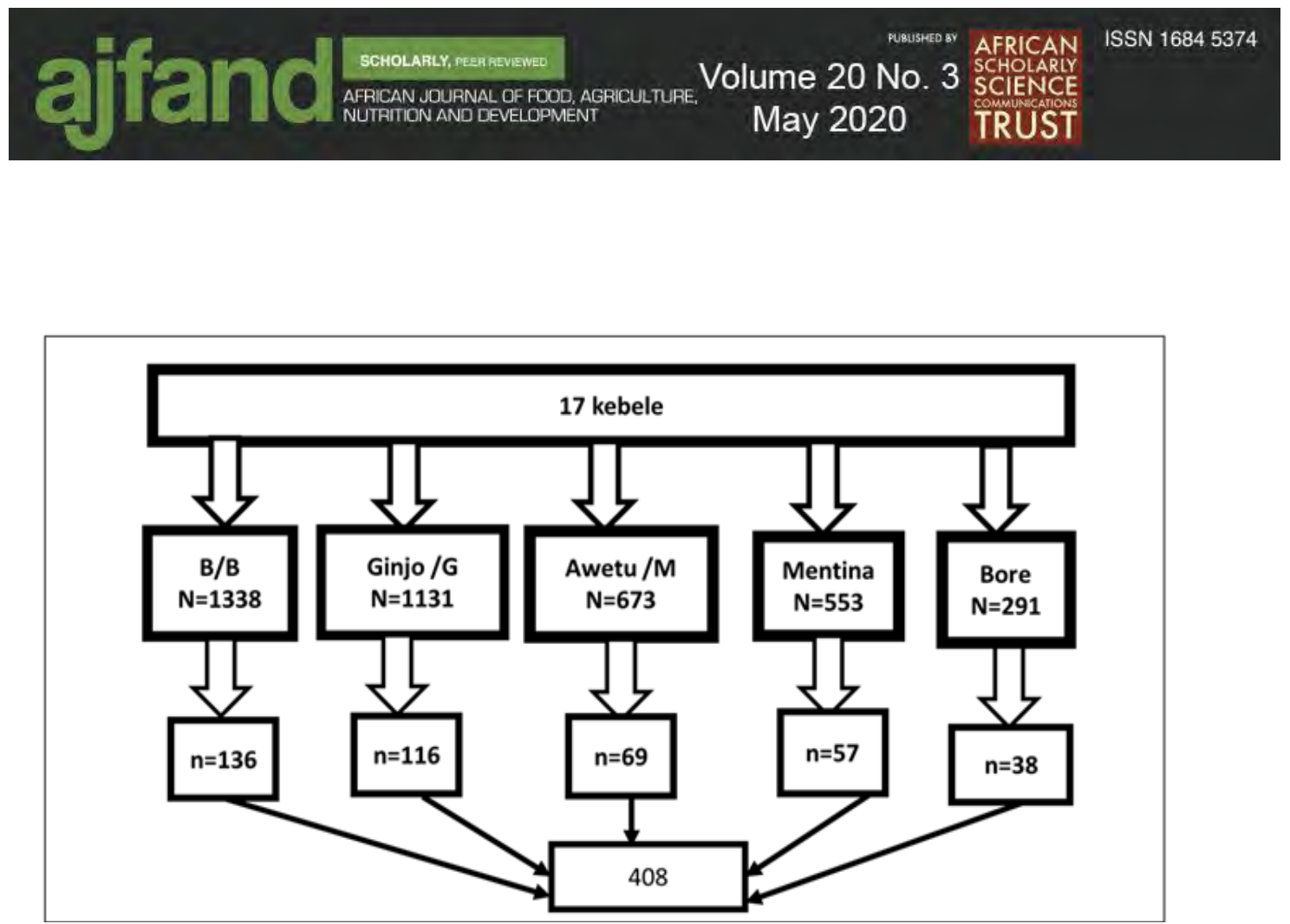

Figure 1: Schematic Presentation of the Sampling Technique

\section{Data collection tools and techniques}

A structured pre-tested questionnaire was used for face to face interview. Questions that assessed socioeconomic, demographic factors, behavior factor, household food security (access), children feeding practice, an infectious disease which was collected by asking mothers/caregivers face to face. Wealth index information of the household was assessed by using ownership of durable assets. Wealth index was ranked and divided into low, medium and high socioeconomic status tertiles. In the data collection process, four trained diploma nurses and one BSc nurse who are fluent in the local language participated as data collectors and supervisor, respectively. Two days training was given to data collectors to discuss each of the questions in the questionnaire and how they should fill it. During data collection, the supervisors followed data collectors and performed quality checks with the principal investigator.

\section{Anthropometric measurements}

The measurements of height and weight were taken from each child using standardized and calibrated equipment. Height of children was taken barefoot by undoing their hair and removing any pins and braids from the hair that could affect the measurement by positioning the subject at the Frankfurt plane using a stadiometer Seca (Seca, Hamburg, Germany, Model 770) and recorded to the nearest $0.1 \mathrm{~cm}$. Weight of children was recorded with light clothing (underwear, t-shirt only) and recorded to nearest $0.1 \mathrm{~kg}$ using UNICEF Seca digital weighing scale (Seca, model 213, Hamburg, Germany).

Mother/caregiver was asked the child's date of birth since the year of birth was frequently reported incorrectly. If birth dates were not recorded or known with certainty, the mother/caregiver was probed for the approximate date of birth based on a local events calendar. Then finally age was calculated by subtracting the date of birth from the date 


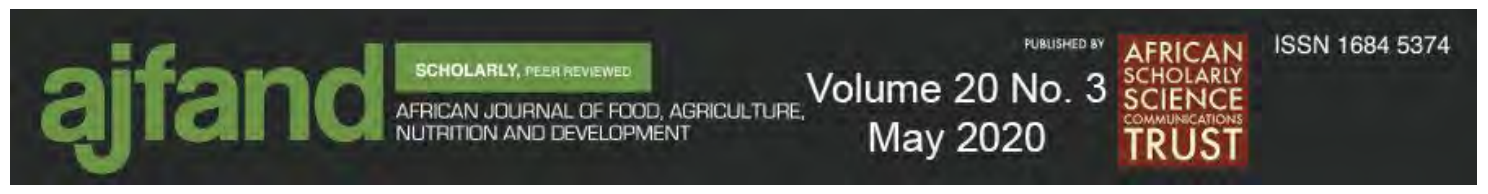

of data collection [17]. The z-score values for the weight for age (WAZ), height for age (HAZ) and weight for height (WHZ) of children from birth to 59 completed months were generated with WHO child growth standards using WHO Anthro 2009 program, version 3.2.2 (WHO, 2007a).

Stunting, underweight and wasting were operationally defined as the proportion of preschool children with values $<-2$ SD from the World Health Organization growth standard median [18].

Assessment of Dietary Diversity Score (DDS)-Children's dietary diversity score was assessed by asking mothers/caregivers to report the different food groups consumed by children over the past 24 hours. Based on USAID guideline we classified DDS in to the following food groups: (1) Grains, roots or tubers (2) Vitamin A-rich fruits and vegetables foods (3) other fruits or vegetables (4) Meat, poultry, fish and seafood (5) Eggs (6) Pulses/legumes/nuts (7) Milk and milk products. United States Agency for International Development (USAID) guidelines suggest not including oils/fats, sugar/honey, and miscellaneous food groups because these food groups do not significantly contribute to a healthful diet and do not contribute to the micronutrient density of the diet so this food group is not included in DDS. Finally, dietary diversity score (DDS) was operationalized [19].

\section{Household Food Insecurity Access Scale (HFIAS) measurement}

Household food insecurity was measured using the Household Food Insecurity Access Scale (HFIAS) that was developed by the Food and Nutrition Technical Assistance (FANTA) project. For HFIAS measurement, each of the questions was asked with a recall period of four weeks (30 days). The respondent was first asked an occurrence question-that is, whether the condition in the question happened at all in the past four weeks (yes or no). If the respondent answered "yes" to an occurrence question, a frequency-of-occurrence question was asked to determine whether the condition happened rarely (once or twice), sometimes (three to ten times) or often (more than ten times) in the past four weeks [20].

\section{Data quality control}

The questionnaire was initially prepared in English then translated to the local language by the expert person and it also retranslated back to English to check the consistency. Training of data collectors was made to ensure the quality of data. A pre-test was conducted on $5 \%$ of preschool children in Hirmata Metina Kebele. After the pre-test, corrections were done on the questionnaires. Measurements of height and weight were taken in duplicate on each child to eliminate the within-examiner error. Weight scale was rested to zero levels with no object on it and placed in the level surface before the measurement was performed. Continuous checkup of scales was carried out for their reliability. The data collection was supervised by the principal investigator. The principal investigator who reviewed every questionnaire for completeness and logical consistency and made corrections on the spot. 


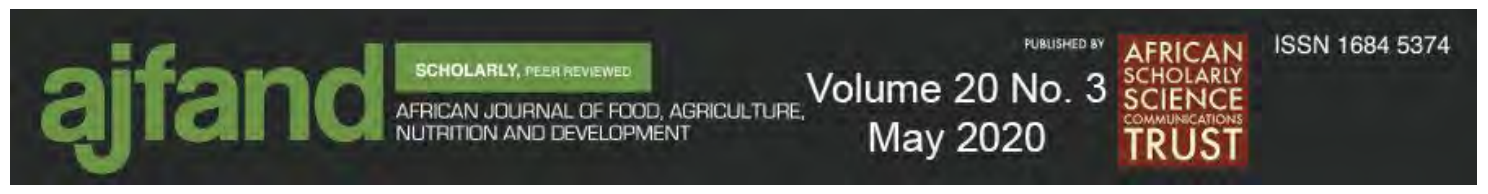

\section{Data Processing and Analysis}

The data were checked for completeness, coded, edited, sorted, cleaned and entered into EPI data version 4.1then exported to SPSS version 20 for analysis. Anthropometric measurements were calculated by using WHO Anthro v3.2.2 software and principal component analyses (PCA) was done for household wealth index ranked into low, medium \& high tertiles. Descriptive statistics (mean $\pm \mathrm{SD}$, frequencies, proportions and tables) and bivariate regression analysis were used to check the independent effect of predictors on outcome variables. Variables with $p$-value $<0.25$ were Candidate for multivariate binary logistic regression to identify a factor that affects nutritional status, preschool children. Significance was declared when the $p$-value was $<0.05$. To evaluate the strength of association between dependent variables and independent variables, both crude odds ratio (COR) and adjusted odds ratio (AOR) with $95 \%$ confidence interval were reported and finally, the result displayed using charts, graphs, and tables.

\section{Ethics approval and consent to participate}

Ethical clearance was obtained from the Ethical Review Board (ERB) of Jimma University Institute of Health, Faculty of Public Health. Official support letter was obtained from Jimma University and Jimma town health bureau for each representative Kebeles for conducting the study. Written and informed consents were secured from each participant by explaining the purposes and the importance of the study \& confidentiality were maintained at all levels of the study. Child assent was taken for anthropometric measurements and the respondents had the right to refuse or withdraw from participation at any time and confidentiality of information collected from each study participant was maintained.

\section{RESULTS AND DISCUSSION}

In this study, data were collected to determine the prevalence of undernutrition and associated factors that might be expected to affect stunting and wasting from a total sample of 408 mothers/caregivers and their 36-59 month old children, giving a response rate of $100 \%$.

\section{Socio-demographic and economic characteristics of study participants}

Most of studied children were females 211 (51.7\%), aged between 48-59 months were 211 (51.7\%), child attend school 231 (56.6), 2th-5th 305 (74.8\%) in their birth order, their birth size were average 324 (79.6), and children caregiver were both mother and father $364(89.2 \%)$ (Table 1).

Regarding socio-demographic characteristics of their mothers/caregiver, the mean $( \pm \mathrm{SD})$ age of study participant were $(30.2 \pm 4.44)$, majority of respondents were married $369(90.4 \%)$ and housewives (40.9\%). Concerning respondents' religion larger proportions $170(41.7 \%)$ were Muslim followed by Orthodox $145(35.5 \%)$ by their religion, while $181(44.3 \%)$ were Oromo followed by Amara $87(21 \%)$ by their ethnicity. With regard to educational status mothers/caregivers, 237 (58.1) had completed primary/secondary school level of education. Two thirds of study participants had five or above family size $275(67.4 \%)$ and more than one third were from middle SES 151 


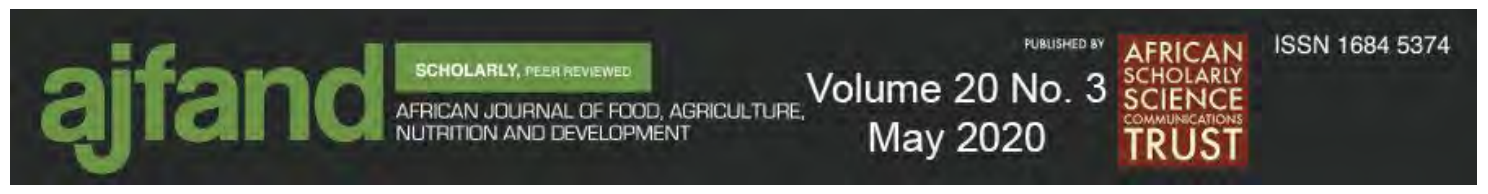

(37\%). Majority of the households were food secure in 244 (59.8\%) while 164 (40.2\%) were food insecure (Table 2).

\section{Health-related characteristics of study participants aged 3-5 years}

Majority of children were fully immunized 372 (91.2\%). More than three quarters of children were not dewormed 350 (85.8) and not provided with vitamin A 382(93.6) while only $58(14.2 \%)$ were dewormed and vitamin A were provided for $6.4 \%$ during the past 6 months. More than two-thirds of children had no illness during the past 2 weeks 301 $(73.8 \%)$ while $107(26.2 \%)$ had illness during the past 2 weeks from these ARI, fevers, and diarrhea were the most common (Table 3 ).

\section{Prevalence of stunting, wasting and underweight among preschool children}

The prevalence of stunting, wasting and underweight in the study participants was $21.8 \%, 17.2 \%$, and $15.2 \%$, respectively. The sex-specific prevalence of stunting, wasting and underweight in boys was $11.8 \%, 7.8 \%$, and $7.1 \%$ while in girls were $10 \%, 9.3 \%$, and $8.11 \%$, respectively. The age-specific prevalence of stunting, wasting and underweight in age groups from $36-47$ months was $10.3 \%, 9.3 \%$, and $6.9 \%$ while in age groups from 48-59 months were $11.5 \%, 7.8 \%$ and $8.3 \%$ (Table 4 ).

\section{Factors associated with stunting among preschool children 36 to 59 months}

The following were the variables with $\mathrm{P}$-value $<0.25$ bivariate logistic regression analysis; child sex, marital status, maternal education, father's education, father's occupation, mother's occupation, family size, caregiver of a child, sharing from the same pot, deworming, WI, food security status (Table 5).

Finally, maternal education, feeding from the same plate, frequency of feeding per day and house hold food security status were all significantly associated with $p$-value $<0.05$.

\section{Factors associated with undernutrition}

This study showed that children from food-insecure households were 3.7 times more likely to be stunted as compared to children from food-secure households [AOR=3.731, $(95 \% \mathrm{CI}=2.037-6.836)]$. Similarly, children whose mothers had no formal education were 3.9 times more likely to be stunted as compared to children whose mothers had the educational status of college/university $[\mathrm{AOR}=3.98 ;(95 \% \mathrm{CI}=1.206-13.127)]$. In addition, children who shared food from the same plate were 2.2 times more likely to be stunted than their counterparts $[\mathrm{AOR}=2.228 ;(95 \% \mathrm{CI}=1.251-3.971)]$ and children who feed one to two times per day were 2.8 times more likely to be stunted as compared to those who feed four to five times per day $[\mathrm{AOR}=2.82(95 \% \mathrm{CI}=1.251-3.971)]$ (Table $5)$.

\section{Factors associated with wasting among preschool children 36 to 59 months}

The following were variables with $\mathrm{P}$ value less than 0.25 in bivariate logistic regression and candidates for multivariable logistic regression: daycare center, birth order, birth interval, maternal age, number of under-five, household family size, maternal education, paternal education, mother occupation, wealth index, diarrhea, fever, sharing the same plate, DDS, frequency of feeding and household food security status. 


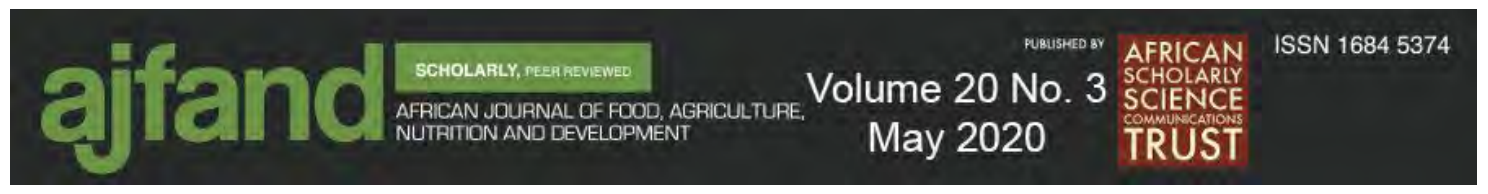

A table below shows, factors associated with wasting on multivariable logistic regression analyses, after adjusting for all other variables were family size, wealth index, age of mother and fever during past 2 weeks (Table 6).

This study showed that children from low socioeconomic status were 3.4 times more likely to be wasted as compared to those children from high socioeconomic household $[\mathrm{AOR}=3.453(95 \% \mathrm{CI}=1.255-9.510)]$. Similarly, children from family size of five and above were 3 times more likely to be wasted than those children from family size less than five $[\mathrm{AOR}=3.090(95 \% \mathrm{CI}=1.198-7.972)]$. In addition, children having fever prior to study period were 2.3 times more likely to be wasted as compared to their counterparts $[\mathrm{AOR}=2.353(95 \% \mathrm{CI}=1.081-5.2)]$. Furthermore, the odds of being wasted among children whose maternal age 31-40 were 2.2 times as compared to those children whose maternal age 20-30 years $[\mathrm{AOR}=2.244(95 \% \mathrm{CI}=1.135-4.438)]$ (Table 6).

This study indicated that undernutrition was a problem in Jimma town where the prevalence of stunting, underweight and wasting were about $21.8 \%, 15.2 \%$, and $17.2 \%$, respectively. These prevalence rates of undernutrition indicated that preschool children of this study area were in a better condition compared to undernutrition reported by some other studies. This study showed that the prevalence of stunting and underweight were lower than national and regional prevalence according to 2016 EDHS report $(36 \%$ \& $24 \%$ ) but the prevalence of wasting supersedes the national and regional prevalence of wasting which was $10 \%$ according to 2016 EDHS report [15].

The results of this study indicated that the prevalence of stunting and underweight were lower, while the prevalence of wasting was a little higher as compared with a community cross-sectional study conducted in Gobu Sayo Woreda, East Wollega, 49\%, and 34.1\% were stunted and underweight respectively while $12.5 \%$ were wasted [21]. Similarly, this study showed that the prevalence of stunting, underweight and wasting were lower as compared with a study done in Hawassa city which showed the prevalence of $53.1 \%$, $43.6 \%$ and $28.2 \%$, respectively [22]. This difference might be due to the study period, study area and sample size.

Although it was not statistically significant, this study revealed that the prevalence of wasting and underweight among female children was slightly higher than male children while the prevalence of stunting was higher among male children. The prevalence of stunting, underweight and wasting was $10 \%, 9.3 \%$ and $8.1 \%$ among female children, while it was $11.8 \%, 7.8 \%$ and $7.9 \%$ among male children respectively. This is similar to the study done in sub-Saharan Africa where stunting affected more boys (42\%) than girls $(36 \%)$ [1]. Also, study done in Kenya showed that boys were more likely to be stunted $(40.3 \%)$ than girls $(33.5 \%)$ but both wasting and underweight were more common among boys $(21.6 \% \& 6.3 \%)$ as compared to girls $(18.6 \%$ and $4.5 \%)$ in contrast to our study findings [23].

This study also revealed that undernutrition among the study children showed variation by age. Even though the age of the child in this study was not significantly associated with stunting, underweight and wasting, the older children were more likely to be stunted $(11.5 \%)$ and underweight $(8.3 \%)$, compared to younger children with $10.3 \%, 6.9 \%$, 


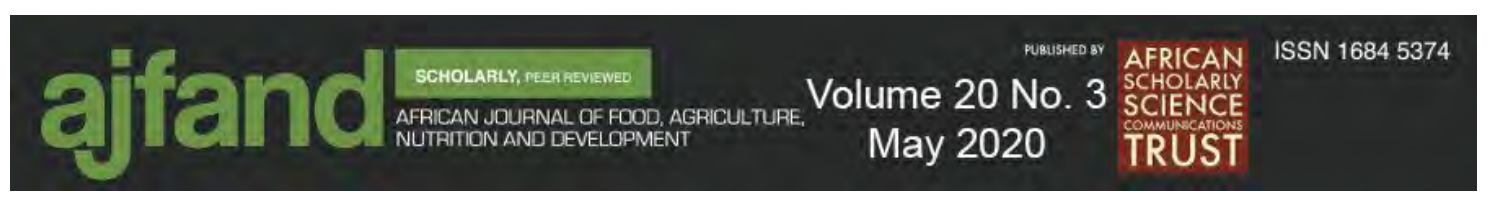

respectively. These results were consistent with those in studies done in centers in Masinga Sub County, Machakos County, Kenya [23].

This study showed that children from food-insecure households were 3.7 times stunted as compared to children from food-secure households. This finding was comparable with the study done among preschool children in Gambella Town (Ethiopia) which showed that children from food-insecure households were about 2.9 more likely to be stunted as compared to those children from food-secure households [24].

Similarly, this study showed that children whose mothers had no formal education were 3.9 times stunted as compared to children whose mothers had the educational status of college/university. This supports a study done on household structure and children's nutritional status in Ethiopia which showed that children born of mothers with no education as a reference, the odds of stunting decreased by $11 \%$ and $39 \%$ for children born to mothers with primary education, and secondary and above level of education, respectively [25].

This positive effect of maternal education on child nutrition could be due to maternal education's improvement on childcare and feeding practices including healthcareseeking behaviors. It also improved income and decision making power augments maternal investment on children's wellbeing. Similarly, a study done on Maternal education and child nutritional status in Bolivia identified five pathways through which maternal education influences child health depending on previous empirical works: improved socio-economic status, health knowledge, modern attitudes towards health care, female autonomy, and reproductive behaviors [26].

Besides, this study revealed children who share food from the same plate were 2.2 times stunted than counterparts, while those children who feed one to two times per day were 2.8 times stunted as compared to those who feed four to five times per day. This supports findings of a study done at Gobu Sayo Woreda, East Wollega where preschool children who got food three times per day were $2.56 \%$ more likely at risk of malnutrition when compared with preschool children who fed food four times per day [21]-and also similar to a study done at Hidabu Abote District where children who ate food three times per day were at risk of malnutrition [27].

These findings could be due to the fact that children at this age start feeding out of the family pot (common family food) where they are exposed to inappropriate feeding (in terms of quantity and quality). These children also often receive less attention from parents or caregivers, a behavior that could affect both the frequency and quality of meals given. Eating adequate food by children is an essential component as they pass through the critical stages of growth and development. Pulling food from a common pot rather than children receiving special individual portions may predispose them to a higher risk for undernutrition because the young may not be able to compete for food in this situation.

This study also showed that children from low socioeconomic status were 3.4 times wasted as compared to those children from the high socio-economic households. Similar 


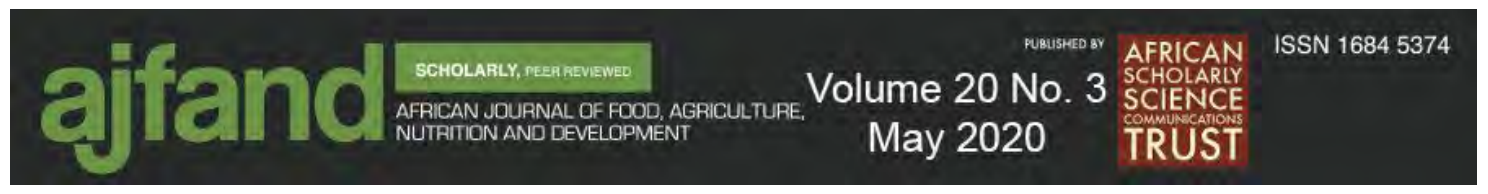

to this study done on household structure and children's nutritional status in Ethiopia had shown that the improvement in the socio-economic status of households to the category of "high" reduced the odds of child malnutrition by at least $28 \%$ [25].

This study showed that children from a family size of five and above were 3 times wasted than those children from family size less than five. This study supports the study done in the Afar Regional State of Ethiopia which showed that larger family size has an adverse effect on the nutritional status of a child [29]. Similarly, a study done in Gobu Sayo Woreda, East Wollega showed that family size was significantly associated with wasting [21]. This might be due to children who could not get adequate and balanced food required for their growth and development as family size increases especially when economically inactive members in the household increases relative to a number of an economically active member of the household.

In addition, children having a fever prior to the study period were 2.3 times more likely to be wasted as compared to their counterparts. Major illnesses and infections such as diarrhea and malaria can damage a child's digestive system to the extent where even a nutritious and adequate diet cannot be absorbed into the body, thus posing the risk of undernutrition [1].

Furthermore, this study found out that the odds of being wasted among children whose maternal age was 31-40 were 2.2 times as compared to those children whose maternal age was 20-30 years. This study supports the study done in the Afar Regional State of Ethiopia, which showed that malnourished children were cared for by elderly mothers when compared to normal children. This study disagrees with other studies that indicated that undernutrition was more prevalent among children born of mothers under the age of 34 years [28]. The variation in this study could be due to the increased knowledge and use of technology among the young mothers that may be changing the trend.

\section{CONCLUSION}

There existed a substantial level of stunting and wasting among preschool children. Maternal education, feeding on the same plate, frequency of feeding per day and household food security status were independent predictors of stunting. Factors associated with wasting were family size, wealth index, age of mother and fever during the past 2 weeks. Based on the findings of the study, the following points are recommended for the government, ministry of health, health offices of Jimma town and other responsible bodies on possible improvements on nutritional status of preschool children.

For healthcare providers, improve household access and use of health services will go a long way promoting healthy environments and reduce the prevalence of infectious diseases. Promotion of better child feeding practice should be integrated into the health care setting for preschool children.

For governmental and non-governmental organization, Community based nutrition program should be strengthened with nutrition-sensitive interventions directed at 


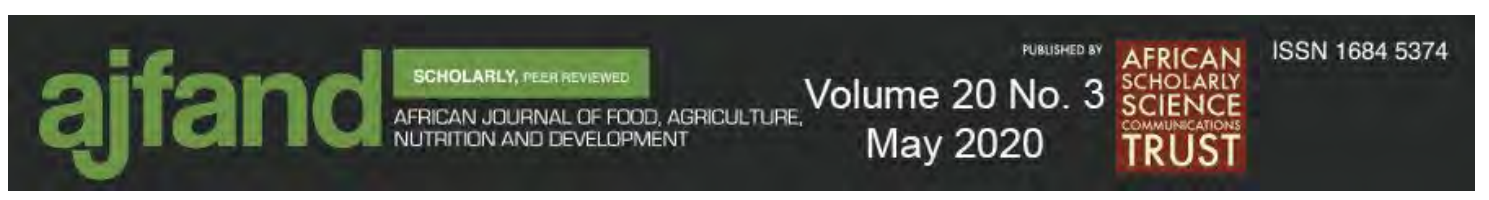

household food security. Nutritional education by health extension workers should be strengthened to improve the feeding practice of parents on appropriate children feeding. For the regional health office, nutrition surveillance needs to be done continuously and special attention should be given for all undernourished children. Nutritional intervention should be implemented in the study for all those undernourished children.

Promotion of optimal feeding, food security measures and better health care delivery are vitally important in such a setting.

\section{Strength and Limitation of the study}

Strength: The study design was a community-based study

Limitation: Since the study was dependent on self-report, there might be recall bias, although efforts were made to minimize them during data collection.

Use of only 24 hours of dietary recall to assess dietary intake may not be reflective of the usual intake of the study subjects due to its inherent limitations.

\section{Authors' contributions}

The authors' responsibilities were as follows: BG, KH \& MST designed the study. BG supervised collected and ensured quality of the data. BG, KH \& MST analyzed and interpreted the data. All authors critically reviewed the manuscript. After all authors gave final approval of the paper to be published, MST, the corresponding author did the analysis \& drafted the manuscript had the responsibility to submit the manuscript for publication.

\section{Acknowledgements}

We would like to pass our appreciation to mothers who participated in the study and also like to pass our deepest gratitude for the research office of Jimma University Institute of Health, Faculty of Public Health for allowing us to conduct this research. Finally, we would like to thank Jimma town health office for their excellent cooperation in the achievement of our study.

\section{Competing interests}

The authors announce that they have no conflicting interests. 


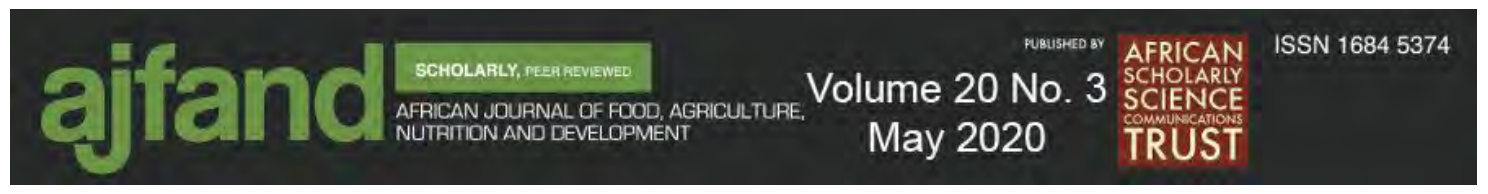

Table 1: Socio demographic characteristics of preschool children aged 36-59 months in Jimma town, South West Ethiopia, March 1 to April 15, 2018

\begin{tabular}{|c|c|c|}
\hline Variable & Frequency $(n=408)$ & Percent \% \\
\hline \multicolumn{3}{|l|}{ Sex } \\
\hline Male & 197 & 48.3 \\
\hline Female & 211 & 51.7 \\
\hline \multicolumn{3}{|l|}{ Age in month: } \\
\hline $36-47$ & 197 & 48.3 \\
\hline $48-59$ & 211 & 51.7 \\
\hline Mean age of child & \multicolumn{2}{|l|}{$47.5 \pm 7.19$} \\
\hline \multicolumn{3}{|l|}{ Educational status child } \\
\hline Not attended & 177 & 43.4 \\
\hline Attended & 231 & 56.6 \\
\hline \multicolumn{3}{|l|}{ Birth weight } \\
\hline Low & 45 & 11 \\
\hline Average & 324 & 79.4 \\
\hline High & 39 & 9.6 \\
\hline \multicolumn{3}{|l|}{ Birth order } \\
\hline $1^{\text {st }}$ born & 89 & 21.8 \\
\hline $2^{\text {nd }}$ to $5^{\text {th }}$ birth & 305 & 74.8 \\
\hline Above $5^{\text {th }}$ birth & 14 & 3.4 \\
\hline \multicolumn{3}{|l|}{ Caregiver of a child } \\
\hline Both mother \& father & 364 & 89.2 \\
\hline Single/Relatives & 44 & 10.8 \\
\hline
\end{tabular}




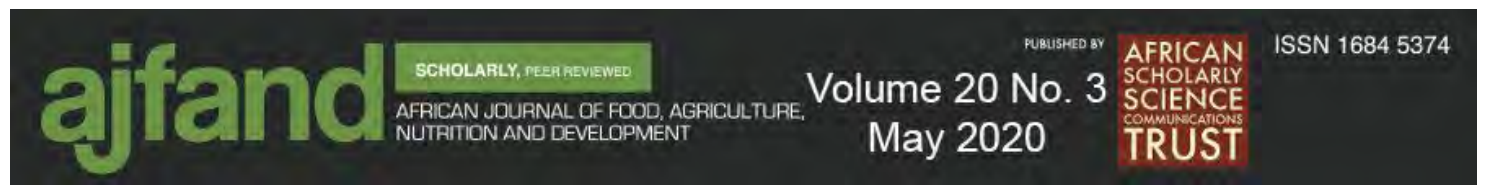

Table 2: Socio-economic and demographic characteristics of mothers/caregivers and their children in Jimma town, South West Ethiopia, March 1 to 15 April, 2018

\begin{tabular}{|c|c|c|}
\hline Variable & Frequency $(n=408)$ & Percent \% \\
\hline \multicolumn{3}{|l|}{ Age mother } \\
\hline $20-30$ & 239 & 58.6 \\
\hline $31-40$ & 169 & 41.5 \\
\hline Mean age $( \pm \mathrm{SD})$ & \multicolumn{2}{|l|}{$30.19 \pm 4.439$} \\
\hline \multicolumn{3}{|l|}{ Marital status } \\
\hline Married & 369 & 90.4 \\
\hline Divorced /widowed/ single & 39 & 9.6 \\
\hline \multicolumn{3}{|l|}{ Religion } \\
\hline Muslim & 170 & 41.7 \\
\hline Orthodox & 145 & 35.5 \\
\hline Protestant & 80 & 19.6 \\
\hline Other* & 13 & 3.2 \\
\hline \multicolumn{3}{|l|}{ Ethnicity: } \\
\hline Oromo & 181 & 44.3 \\
\hline Amhra & 87 & 21.3 \\
\hline Dawuro & 46 & 11.3 \\
\hline Kafa & 39 & 9.6 \\
\hline Guraghe & 36 & 8.8 \\
\hline other** & 19 & 4.6 \\
\hline \multicolumn{3}{|l|}{ Family size } \\
\hline$<5$ & 133 & 32.8 \\
\hline \multirow[t]{2}{*}{$\geq 5$} & 275 & 67.4 \\
\hline & \multicolumn{2}{|l|}{$5.23 \pm 1.52$} \\
\hline \multicolumn{3}{|l|}{ Mean of family size } \\
\hline \multicolumn{3}{|l|}{ Number of under-five } \\
\hline One child & 286 & 70.1 \\
\hline
\end{tabular}




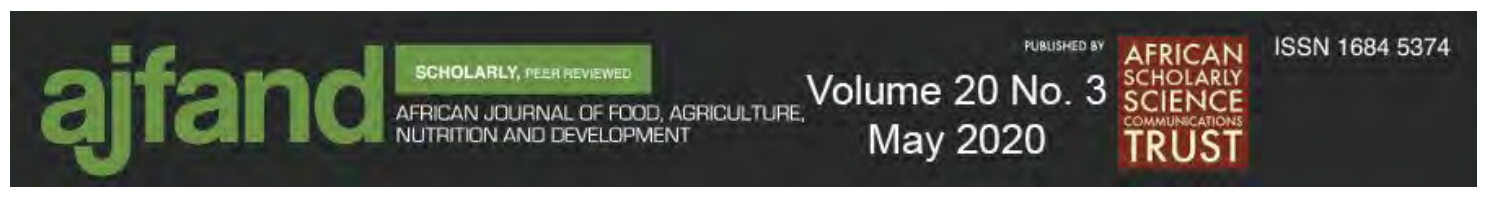

\begin{tabular}{|c|c|c|}
\hline & & \\
\hline Two children & 113 & 27.7 \\
\hline Three children & 9 & 2.2 \\
\hline Educational status of mother & & \\
\hline No formal education & 73 & 17.9 \\
\hline Primary/ Secondary school & 237 & 58.1 \\
\hline College/university & 98 & 24 \\
\hline Educational status of father & & \\
\hline No formal education & 42 & 10.3 \\
\hline Primary/ Secondary school & 241 & 59.1 \\
\hline College/university & 125 & 30.6 \\
\hline Mother occupation & & \\
\hline Government work & 78 & 19.1 \\
\hline Self-employed & 163 & 40 \\
\hline Housewife & 167 & 40.9 \\
\hline Father occupation & & \\
\hline Government work & 91 & 22.3 \\
\hline Self-Employed & 247 & 60.5 \\
\hline Daily labor/Unemployed & 70 & 17.5 \\
\hline Wealth index & & \\
\hline Low & 121 & 29.7 \\
\hline Medium & 151 & 37 \\
\hline High & 136 & 33.3 \\
\hline Food security status & & \\
\hline Food secure & 244 & $59.8 \%$ \\
\hline Food insecure & 164 & 40.2 \\
\hline
\end{tabular}

Religion other * catholic

Ethnicity * Tigre, Silxe, Yem 


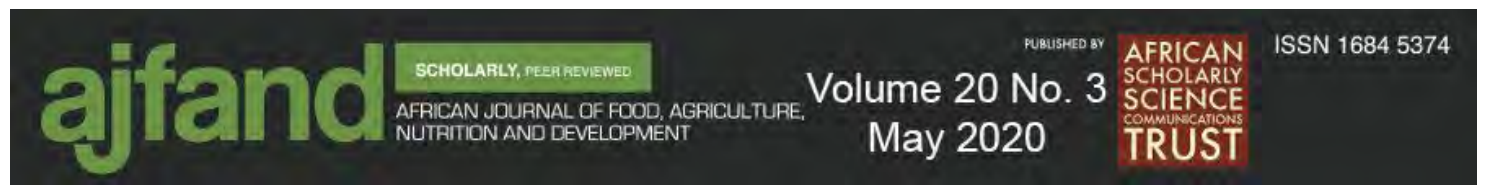

Table 3: Health-related Characteristics of preschool children 36-59 months age in Jimma town, South West Ethiopia, from March 1 to April 15, 2018

\begin{tabular}{|c|c|c|}
\hline Variable & Frequency $(n=408)$ & Percent \% \\
\hline \multicolumn{3}{|l|}{ Immunization status } \\
\hline Fully immunized & 373 & 91.4 \\
\hline Incompletely Immunized & 31 & 7.6 \\
\hline Not immunized & 4 & 1 \\
\hline \multicolumn{3}{|l|}{ Deworming tablet } \\
\hline Yes & 58 & 14.2 \\
\hline No & 350 & 85.8 \\
\hline \multicolumn{3}{|l|}{ Vitamin A supplementation } \\
\hline Yes & 26 & 6.4 \\
\hline No & 382 & 93.6 \\
\hline \multicolumn{3}{|l|}{ Had been sick in the past 2 weeks } \\
\hline Yes & 107 & 26.2 \\
\hline No & 301 & 73.8 \\
\hline \multicolumn{3}{|l|}{ Identified problem } \\
\hline ARI & 74 & 18.1 \\
\hline Fever & 82 & 20.1 \\
\hline Diarrhea & 30 & 7.4 \\
\hline Other* & 27 & 6.6 \\
\hline
\end{tabular}

* Measles, skin rash, ear discharge and eye discharge 


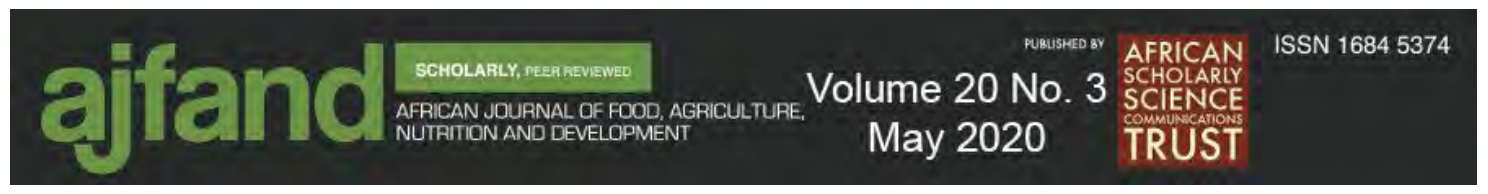

Table 4: Proportion of children with malnutrition as measured by 3 different anthropometric measurements among preschool children 36-59 months in Jimma town, Southwest Ethiopia, March 1 to April 15, 2018

\begin{tabular}{|l|l|l|}
\hline $\begin{array}{l}\text { Nutritional status as } \\
\text { determined by }\end{array}$ & $\begin{array}{l}\mathbf{z - 2 S D} \\
\text { No (\%) } \\
\text { No (\%) }\end{array}$ \\
\hline Stunting & $89(21.8)$ & $319(78.2)$ \\
\hline Underweight & $62(15.2)$ & $346(84.2)$ \\
\hline Wasting & $70(17.2)$ & $338(82.8)$ \\
\hline
\end{tabular}

Table 5: Multivariable logistic regression model predicting the likelihood of being stunted among preschool children 36-59 months in Jimma town, Southwest Ethiopia, March 1 to April 15, 2018

\begin{tabular}{|c|c|c|c|c|c|c|c|}
\hline \multirow[t]{2}{*}{ Variable } & \multicolumn{2}{|l|}{ Stunting } & \multirow[t]{2}{*}{ COR } & \multirow[t]{2}{*}{ AOR } & \multicolumn{2}{|c|}{$95 \%$ CI } & \multirow[t]{2}{*}{ P-value } \\
\hline & $\begin{array}{l}\text { Yes } \\
\text { N (\%) }\end{array}$ & $\begin{array}{l}\text { No } \\
\text { N (\%) }\end{array}$ & & & Lower & Upper & \\
\hline $\begin{array}{ll}\text { Sex: } & \text { Male } \\
& \text { Female }\end{array}$ & $\begin{array}{c}41(10) \\
48(11.8)\end{array}$ & $\begin{array}{l}170(41.7) \\
149(36.5)\end{array}$ & $\begin{array}{l}0.749 \\
1\end{array}$ & $\begin{array}{l}0.843 \\
1\end{array}$ & 0.492 & 1.445 & 0.534 \\
\hline $\begin{array}{l}\text { Marital status } \\
\text { Married } \\
\text { Divorced /widowed/ single }\end{array}$ & $\begin{array}{l}84(20.6) \\
5(1.2)\end{array}$ & $\begin{array}{l}285(69.9) \\
34(8.3)\end{array}$ & $\begin{array}{l}2.004 \\
1\end{array}$ & $\begin{array}{l}1.470 \\
1\end{array}$ & 0.475 & 4,551 & 0.504 \\
\hline $\begin{array}{l}\text { Family size } \\
<5 \\
\geq 5\end{array}$ & $\begin{array}{l}19(4.6) \\
70(17.2)\end{array}$ & $\begin{array}{l}114(27.9) \\
205(50.2)\end{array}$ & $\begin{array}{l}1 \\
2.049\end{array}$ & $\begin{array}{l}1 \\
1.648\end{array}$ & 0.858 & 3.168 & 0.134 \\
\hline $\begin{array}{l}\text { Educational status of motl } \\
\text { No formal education } \\
\text { Primary/ Secondary } \\
\text { College/university }\end{array}$ & $\begin{array}{l}33(8.1) \\
46(11.3) \\
10(2.5\end{array}$ & $\begin{array}{l}40(9.8) \\
191(46.8) \\
88(21.6)\end{array}$ & $\begin{array}{l}7.260 \\
2.119 \\
1\end{array}$ & $\begin{array}{l}3.978 \\
1.414 \\
1\end{array}$ & $\begin{array}{l}1.206 \\
0.511\end{array}$ & $\begin{array}{l}13.127 \\
3.913\end{array}$ & $\begin{array}{l}\mathbf{0 . 0 2 3} * \\
0.505\end{array}$ \\
\hline $\begin{array}{l}\text { Educational status of fathe } \\
\text { No formal education } \\
\text { Primary/ Secondary } \\
\text { College/university }\end{array}$ & $\begin{array}{l}12(2.9) \\
62(15.2) \\
15(3.7\end{array}$ & $\begin{array}{l}30(7.3) \\
179(43.9) \\
110(27) \\
\end{array}$ & $\begin{array}{l}2.933 \\
2.540 \\
1\end{array}$ & $\begin{array}{l}0.463 \\
0.892 \\
1\end{array}$ & $\begin{array}{l}0.137 \\
0.349\end{array}$ & $\begin{array}{l}1.564 \\
2.275\end{array}$ & $\begin{array}{l}0.215 \\
0.810\end{array}$ \\
\hline $\begin{array}{c}\text { Mother occupation } \\
\text { Government work } \\
\text { Self-employed } \\
\text { Housewife }\end{array}$ & $\begin{array}{l}9(2.2) \\
36(8.8) \\
44(10.8)\end{array}$ & $\begin{array}{l}69(16.9) \\
127(31.1) \\
123(30.1)\end{array}$ & $\begin{array}{l}0.365 \\
0.792 \\
1\end{array}$ & $\begin{array}{l}0.944 \\
0.930 \\
1\end{array}$ & $\begin{array}{l}0.391 \\
0.513\end{array}$ & $\begin{array}{l}2.797 \\
1.688\end{array}$ & $\begin{array}{l}0.917 \\
0.812\end{array}$ \\
\hline
\end{tabular}




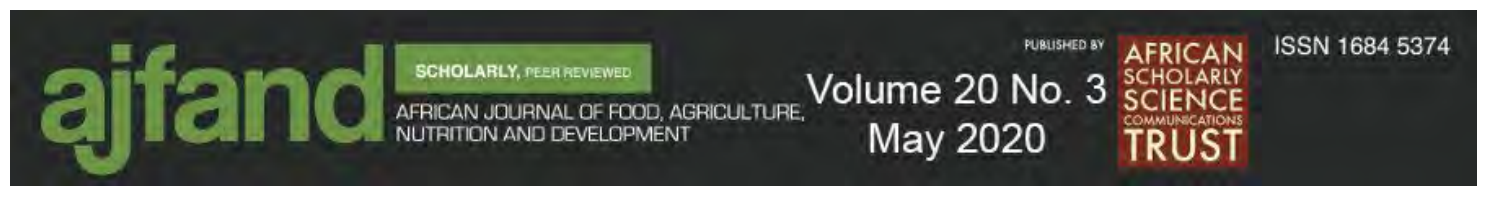

\begin{tabular}{|c|c|c|c|c|c|c|c|}
\hline $\begin{array}{l}\text { Father occupation } \\
\text { Government work } \\
\text { self-employer } \\
\text { Daily labor/Unemployed }\end{array}$ & $\begin{array}{l}9(2.2) \\
67(16.4) \\
13(3.2)\end{array}$ & $\begin{array}{l}82(20.1) \\
180(44.1) \\
57(14)\end{array}$ & $\begin{array}{l}0.481 \\
1.632 \\
1\end{array}$ & $\begin{array}{l}0.516 \\
0.747 \\
1\end{array}$ & $\begin{array}{l}0.188 \\
0.311\end{array}$ & $\begin{array}{l}1.414 \\
1.799\end{array}$ & $\begin{array}{l}0.198 \\
0.516\end{array}$ \\
\hline $\begin{array}{l}\text { Wealth index } \\
\text { Low } \\
\text { Medium } \\
\text { High }\end{array}$ & $\begin{array}{l}36(8.8) \\
38(9.3) \\
15(3.7)\end{array}$ & $\begin{array}{l}85(20.8) \\
113(27.7) \\
121(29.6)\end{array}$ & $\begin{array}{l}3.416 \\
2.713 \\
1\end{array}$ & $\begin{array}{l}0.837 \\
1.377 \\
1\end{array}$ & $\begin{array}{l}0.346 \\
0.631\end{array}$ & $\begin{array}{l}2.024 \\
3.003\end{array}$ & $\begin{array}{l}0.693 \\
0.421\end{array}$ \\
\hline $\begin{array}{c}\text { Food security status } \\
\text { Food insecure } \\
\text { Food secure }\end{array}$ & $\begin{array}{l}56(13.7) \\
33(8.1)\end{array}$ & $\begin{array}{l}108(26.5) \\
211(51.7)\end{array}$ & $\begin{array}{l}3.315 \\
1\end{array}$ & $\begin{array}{l}3.731 \\
1\end{array}$ & 2.037 & 6.836 & $0.000 * *$ \\
\hline $\begin{array}{c}\text { Deworming tablet } \\
\text { Yes } \\
\text { No }\end{array}$ & $\begin{array}{l}6(1.5) \\
83(20.3)\end{array}$ & $\begin{array}{l}52(12.7) \\
267(65.4)\end{array}$ & $\begin{array}{l}1 \\
2.694\end{array}$ & $\begin{array}{l}1 \\
2.688\end{array}$ & 0.960 & 7.522 & 0.06 \\
\hline $\begin{array}{l}\text { Frequency of feeding per } \\
\text { day } \\
\begin{array}{c}\text { 1-2times } \\
\text { Three times } \\
4-5 \text { times } \\
\end{array}\end{array}$ & \begin{tabular}{|l|}
$12(2.9)$ \\
$61(14.9)$ \\
$16(3.9)$ \\
\end{tabular} & $\begin{array}{l}29(7.1) \\
166(40.7) \\
124(30.4) \\
\end{array}$ & $\begin{array}{l}3.207 \\
2.848 \\
1 \\
\end{array}$ & $\begin{array}{l}2.819 \\
1.842 \\
1 \\
\end{array}$ & $\begin{array}{l}1.101 \\
0.898\end{array}$ & $\begin{array}{l}7.857 \\
3.778\end{array}$ & $\begin{array}{l}\mathbf{0 . 0 4 8}^{*} \\
0.096\end{array}$ \\
\hline $\begin{array}{c}\text { Sharing from the same plate } \\
\text { Yes } \\
\text { No }\end{array}$ & $\begin{array}{l}40(9.8) \\
49(12)\end{array}$ & $\begin{array}{l}66(16.2) \\
253(62)\end{array}$ & $\begin{array}{l}3.129 \\
1\end{array}$ & $\begin{array}{l}2.228 \\
1\end{array}$ & 1.251 & 3.971 & $0.007 *$ \\
\hline
\end{tabular}

NB: * P-value $<0.05$ and **p-value $<0.001$

Hosmer-Lemshow's goodness-of-fit test produce p-value of 0.683 , hence the model was good for the data 


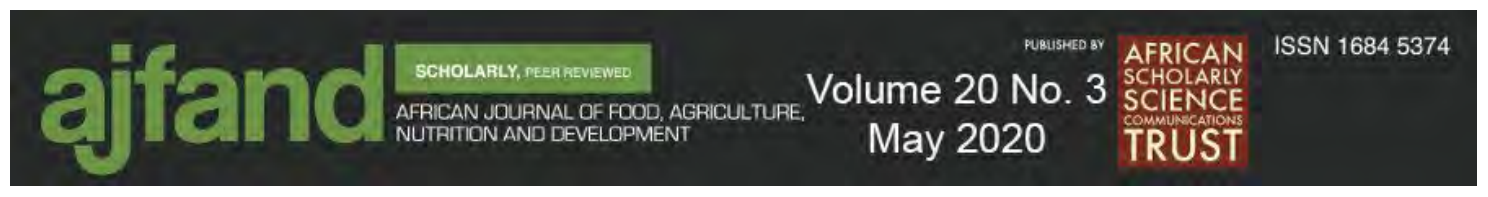

Table 6: Multivariable logistic regression model predicting the likelihood of being wasted among preschool children 36-59 months in Jimma town, Southwest Ethiopia, March 1 to April 15, 2018

\begin{tabular}{|c|c|c|c|c|c|c|c|}
\hline \multirow[t]{2}{*}{ Variable } & \multicolumn{2}{|l|}{ Wasting } & \multirow[t]{2}{*}{ COR } & \multirow[t]{2}{*}{ AOR } & \multicolumn{2}{|c|}{$95 \%$ CI } & \multirow{2}{*}{$\begin{array}{l}\text { P- } \\
\text { value }\end{array}$} \\
\hline & $\begin{array}{l}\text { Yes } \\
\text { N (\%) }\end{array}$ & $\begin{array}{l}\text { No } \\
\text { N (\%) }\end{array}$ & & & Lower & Upper & \\
\hline \multicolumn{8}{|l|}{ Day care center } \\
\hline Not attended & $35(8.6)$ & $142(34.8)$ & 0.724 & 0.852 & 0.438 & 1.657 & 0.637 \\
\hline Attended & $35(8.6)$ & 196(48) & 1 & 1 & & & \\
\hline \multicolumn{8}{|l|}{ Birth order } \\
\hline $1^{\text {st }}$ born & $11(2.7)$ & $78(19.1)$ & 0.106 & 0.756 & 0.293 & 1.949 & 0.563 \\
\hline $2^{\text {nd }}$ to $5^{\text {th }}$ birth & $51(12.5)$ & $254(62.3)$ & 0.151 & 2.983 & 0.614 & 14.504 & 0.175 \\
\hline Above $5^{\text {th }}$ birth & $8(2)$ & $6(1.5)$ & 1 & 1 & & & \\
\hline \multicolumn{8}{|l|}{ Number of under five } \\
\hline One child & $38(9.4)$ & $249(61.3)$ & 0.305 & 0.462 & 0.064 & 3.306 & 0.442 \\
\hline Two children & $29(7.1)$ & $84(20.7)$ & 0.690 & 0.6 & 0.086 & 4.184 & 0.606 \\
\hline Three children & $2(0.5)$ & $4(1)$ & 1 & & & & \\
\hline \multicolumn{8}{|l|}{ Age of mother } \\
\hline $20-30$ & $30(7.4)$ & $209(51.2)$ & 1 & & & & \\
\hline $31-40$ & $40(9.8)$ & $129(31.6)$ & 2.160 & 2.244 & 1.135 & 4.438 & $0.02 *$ \\
\hline \multicolumn{8}{|l|}{ Family size } \\
\hline$<5$ & $9(2.2)$ & $124(30.4)$ & 1 & 1 & & & \\
\hline$\geq 5$ & $61(15)$ & $214(52.4)$ & 3.927 & 3.090 & 1.198 & 7.972 & $0.02 *$ \\
\hline \multicolumn{8}{|l|}{$\begin{array}{l}\text { Educational status of } \\
\text { mother }\end{array}$} \\
\hline No formal education & $29(7.1)$ & $44(10.8)$ & 15.489 & 3.964 & 0.984 & 15.976 & 0.053 \\
\hline Primary/ Secondary & $37(9.1)$ & $200(49)$ & 4.347 & 1.855 & 0.526 & 6.544 & 0.337 \\
\hline College/university & $4(1)$ & $94(23)$ & 1 & 1 & & & \\
\hline $\begin{array}{l}\text { Educational status of } \\
\text { father }\end{array}$ & & & & & & & \\
\hline
\end{tabular}




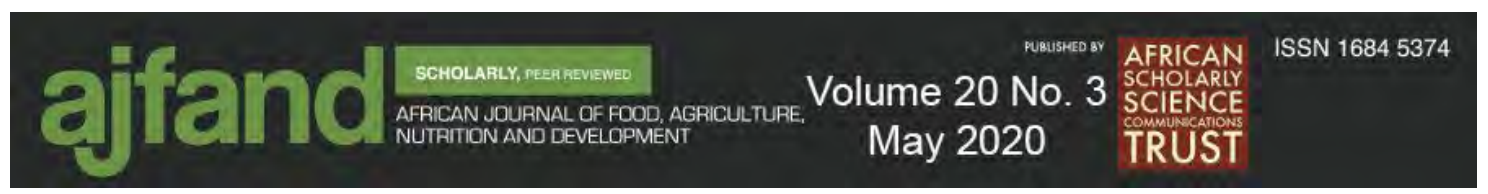

\begin{tabular}{|c|c|c|c|c|c|c|c|}
\hline $\begin{array}{l}\text { No formal education } \\
\text { Primary/ Secondary } \\
\text { College/university }\end{array}$ & $\begin{array}{l}10(2.5) \\
49(12) \\
11(2.7)\end{array}$ & $\begin{array}{l}32(7.8) \\
192(47.1) \\
114(27.9)\end{array}$ & $\begin{array}{l}3.239 \\
2.645 \\
1\end{array}$ & $\begin{array}{l}0.490 \\
0.954 \\
1\end{array}$ & $\begin{array}{l}0.141 \\
0.390\end{array}$ & $\begin{array}{l}1.706 \\
2.337\end{array}$ & $\begin{array}{l}0.262 \\
0.918\end{array}$ \\
\hline \multicolumn{8}{|l|}{ Mother occupation } \\
\hline Government work & $3(0.7)$ & $75(18.4)$ & 0.146 & 0.270 & 0.05 & 1.451 & 0.127 \\
\hline self-employer & $31(7.6)$ & $132(32.4)$ & 0.855 & 0.860 & 0.453 & 1.634 & 0.645 \\
\hline Housewife & $36(8.8)$ & $131(32.1)$ & 1 & 1 & & & \\
\hline \multicolumn{8}{|l|}{ Wealth index } \\
\hline Low & $36(8.8)$ & $85(20.8)$ & 5.336 & 3.453 & 1.255 & 9.502 & $0.016 *$ \\
\hline Medium & $24(5.9)$ & $127(31.1)$ & 2.381 & 2.174 & 0.853 & 5.540 & 0.104 \\
\hline High & $10(2.5)$ & $126(30.9)$ & 1 & 1 & & & \\
\hline \multicolumn{8}{|l|}{ Food security status } \\
\hline Food insecure & $46(11.3)$ & $118(28.9)$ & 1.998 & 1.361 & 0.695 & 2.665 & 0.369 \\
\hline Food secure & $24(5.9)$ & $220(53.9)$ & 1 & 1 & & & \\
\hline Fever: Yes & $22(5.4)$ & $56(13.7)$ & 2.308 & 2.353 & 1.081 & 5.122 & 0.031* \\
\hline No & $48(11.8)$ & $282(69.1)$ & 1 & 1 & & & \\
\hline Diarrhea: Yes & $12(2.9)$ & $18(4.4)$ & 3.678 & 1.204 & 0.363 & 2.892 & 0.964 \\
\hline No & $58(12.2)$ & $304(78.4)$ & 1 & 1 & & & \\
\hline Frequency of feeding & & & & & & & \\
\hline 1-2times & $14(3.4)$ & $27(6.6)$ & 5.066 & 2.811 & 0.939 & 8.412 & 0.065 \\
\hline Three times & $43(10.5)$ & $184(45.1)$ & 2.283 & 1.349 & 0.601 & 3.028 & 0.468 \\
\hline $4-5$ times & $13(3.2)$ & $127(31.1)$ & 1 & 1 & & & \\
\hline Sharing the same plate & & & & & & & \\
\hline Yes & $23(5.6)$ & $83(20.3)$ & 1.503 & 1.348 & 0.674 & 2.698 & 0.398 \\
\hline No & $47(11.5)$ & $255(62.5)$ & 1 & 1 & & & \\
\hline
\end{tabular}

NB: * P-value $<\mathbf{0 . 0 5}$ Hosmer-Lemshow's goodness-of-fit test produce p-value of 0.950 , the model was good for the data 


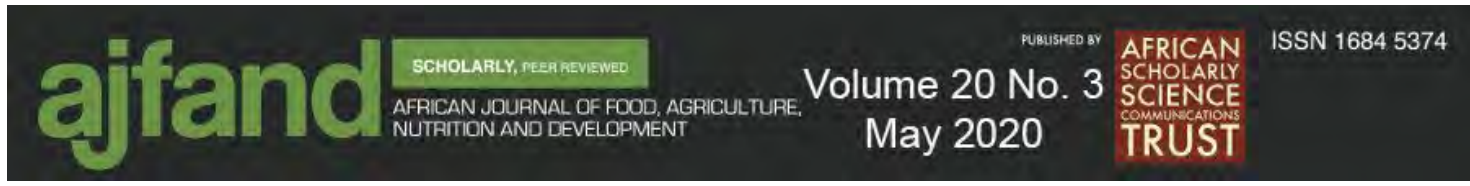

\section{REFERENCES}

1. United Nations Children's Fund (UNICEF). Improving child nutrition: The achievable imperative for global progress. Div Commun UNICEF. 2013, 1-132.

2. Haddad L, Achadi E, Bendech MA, Ahuja A, Bhatia K, Bhutta Z, Blössner M, Borghi E, Colecraft E, de Onis M, Eriksen K, Fanzo J, Flores-Ayala R, Fracassi P, Kimani-Murage E, Nago Koukoubou E, Krasevec J, Newby H, Nugent R, Oenema S, Martin-Prével Y, Randel J, Requejo J, Shyam T, Udomkesmalee E and KS Reddy The Global Nutrition Report 2014: Actions and Accountability to Accelerate the World's Progress on Nutrition. J Nutr. 2015;145(4):663-71.

3. Haddad L Global Nutrition Report. International Food Policy Research Institute. 2015.

4. Robert E Black, Cesar G. Victora, Susan P. Walker, Zulfiqar A. Bhutta, Parul S Christian, Mercedes De Onis, Majid Ezzati, Sally Grantham-Mcgregor, Joanne Katz, Reynaldo Martorell and Ricardo Uauy Maternal and Child Nutrition 1 Maternal and child undernutrition and overweight in low-income and middle-income countries. 2013;6736(13).

5. Rocha C, Constante Jaime $\mathbf{P}$ and $\mathbf{M}$ Ferreira Rea The Global Nutrition Report. Global Nutrition Report - From promise to impact: ending malnutrition by 2030 . 2016, 11-14 p.

6. Adair LS, Fall CH, Osmond C, Stein AD, Martorell R, Ramirez-Zea M, Sachdev HS, Dahly DL, Bas I, Norris SA, Micklesfield L, Hallal P and CG Victora Associations of linear growth and relative weight gain during early life with adult health and human capital in countries of low and middle income: Findings from five birth cohort studies. Lancet. 2013;382(9891):525-34.

7. The World Bank. Repositioning Nutrition as Central to Development. A Strategy for Large-Scale Action. The world Bank. 2006. 246 p.

8. Hoddinott $\mathbf{J}$, Alderman $\mathbf{H}$, Behrman JR, Haddad $\mathbf{L}$ and $\mathbf{S}$ Horton The economic rationale for investing in stunting reduction. Matern Child Nutr. 2013;9(S2):69-82.

9. Government of Ethiopia. National Nutrition Program 2016 - 2020.

10. United Nations Children's Fund (UNICEF). Strategy for improved nutrition of children and women in developing countries. Policy Review Paper E/ICEF/1990/1.6, UNICEF, New York. 1990.

11. Blössner M, Onis M De and A Prüss-üstün Campbell-lendrum D, Corvalán C, Woodward A "Malnutrition Quantifying the health impact at national and local levels," no. 12, 2005. 


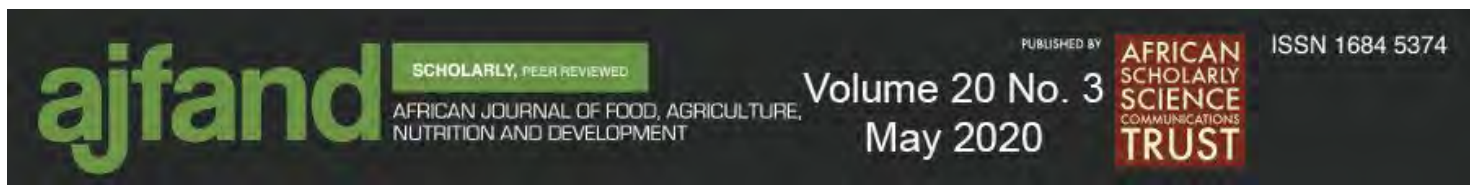

12. UNICEF, WHO, Group WB. Levels and Trends in Child Malnutrition. Jt Child Malnutrition Estim Ed, 2017, 11-12.

13. World Health Organization. World Health Statistics 2016: Monitoring Health for the SDGs. World Health Organization. 2016.

14. United Nations. The Millennium Development Goals Report 2015 Summary. MDG Rep. 2015, 55-8.

15. Central Statistical Agency [Ethiopia] and ICF International. Federal Democratic Republic of Ethiopia Ethiopia Demographic and Health Survey 2016 Key Indicators Report. Ethiopians Water Sector Development Program. 2016.

16.Alemneh K, Sintayehu A, Dejene $\mathbf{H}$ and B Getenesh Intestinal parasitic infections and nutritional status of pre-school children in Hawassa Zuria District, South Ethiopia. African J Microbiol Res . 2017;11(31):1243-51.

17. World Health Organization. WHO AnthroPlus for personal computers manual: software for assessing growth of the world's children and adolescents. Geneva WHO. 2009.

18. WHO Multicentre growth reference study group. WHO Child Growth Standards based on length / height, weight and age. Acta Paediatr. 2006;Suppl 450:76-85.

19. Swindale A and P Bilinsky Household Dietary Diversity Score (HDDS) for measurement of household food access: Indicator guide. Food Nutr Tech Assist. $2006 ; 11$.

20. Coates J, Swindale A and P Bilinsky Household Food Insecurity Access Scale (HFIAS) for measurement of food access: indicator guide. Washington, DC Food Nutr Tech. 2007;(August):Version 3.

21. Sayo G and E Wollega Prevalence of Wasting and Associated Factors among Preschool. Food Sci. Qual Manag. 2014;28:58-66.

22. Wolde T, Belachew $\mathbf{T}$ and $\mathbf{T}$ Birhanu Prevalence of Undernutrition and Determinant Factors among Preschool Children in Hawassa, Southern Ethiopia. 2014;29(July 2015):65-73.

23. Mutua RN, Keriko $\mathbf{J}$ and $\mathbf{J}$ Mutai Factors associated with stunting, wasting and underweight among children aged 2-5 years in early childhood development and education centers in Masinga sub county, Machakos county. Eur J Health Sci. 2017; 1:44-69.

24. Jemal $\mathbf{Z}$, Hassen $\mathbf{K}$ and $\mathbf{T}$ Wakayo Household Food Insecurity and its Association with Nutritional Status among Preschool Children in Gambella Town, Western. J Nutr Food Sci 2016; 6(6):1-7. DOI: 10.4172/2155-9600.1000566 


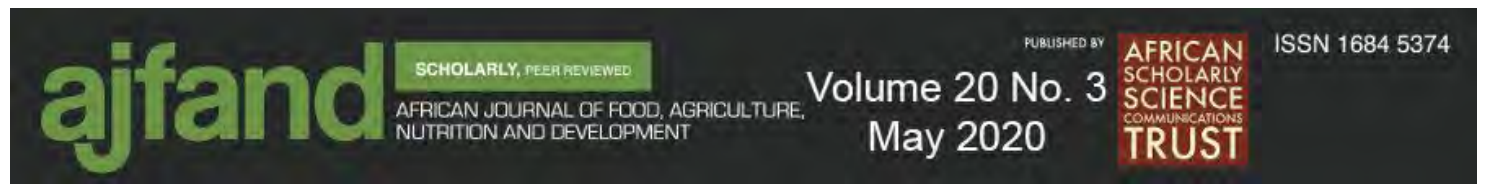

25. Gurmu E and D Etana Household structure and children's nutritional status in Ethiopia. Genus. 2013;69(2):113-30.

26. Frost MB, Forste $\mathbf{R}$ and DW Haas Maternal education and child nutritional status in Bolivia: Finding the links. Soc Sci Med. 2005;60(2):395-407.

27. Mengistu K , Alemu $\mathbf{K}$ and $\mathbf{B}$ Destaw Prevalence of Malnutrition and Associated Factors Among Children Aged 6-59 Months at Hidabu Abote District, North Shewa, Oromia Regional State. Itle 2013.

28. Ahmed N, Barnett I and R Longhurst Determinants of child undernutrition in Bangladesh literature review. MQSUN report 2015.

29. Fentaw R, Bogale A and D Abebaw Prevalence of child malnutrition in agropastoral households in Afar regional State of ethiopia. Nutr Res Pract. 2013;7(2):122-31.

30. Berhanu G, Mekonnen S and M Sisay Prevalence of stunting and associated factors among preschool children: A community-based comparative crosssectional study in Ethiopia. BMC Nutrition. 2018 Dec;4(1):28.

31. UNICEF. UNICEF's approach to scaling up nutrition for mothers and their children. UNICEF, New York: Discussion paper. Programme Division; June 2015.

32. Central Statistical Agency 2010. Population and Housing Census ReportCountry-2007.

33. Daniel WW The Fisher exact test. Biostatistics: A Foundation for Analysis in the Health Sciences. 7th ed. WW Daniel, ed. John Wiley \& Sons Inc., New York, NY. 1999:606-11. 